\title{
Processo produtivo de elementos pré-moldados de concreto armado: detecção de manifestações patológicas
}

\author{
Cleovir José Milani \\ Engenheiro civil, professor do curso de Engenharia Civil da \\ Universidade Tecnológica Federal do Paraná,UTFPR, Rua Itacolomi, \\ 1303, apto 201, centro, Pato Branco, Paraná, (46) 3225-2450, \\ cjmilani@yahoo.com.br
}

\section{Rodrigo Boesing}

Engenheiro civil pela Universidade Tecnológica Federal do Paraná, UTFPR, Rua Tapejara, 520, apto 204B, Pato Branco, PR, rodrigoboesing@hotmail.com

\section{Resumo}

O estudo correlaciona as patologias com o processo produtivo de elementos pré-moldados de concreto que vêm sendo empregados por empresas que atuam na região oeste de Santa Catarina e sudoeste do Paraná. O trabalho identifica as patologias que são originadas ainda no processo de produção, investiga as causa de tais patologias e propõe medidas mitigadoras. Fundamentado em visitas técnicas, o estudo verificou como ocorre a produção dos pré-moldados, englobando itens que abrangem desde o recebimento e estocagem da matériaprima, preparação do concreto, formas, armaduras, logística, até a expedição do produto acabado para o consumidor.
\end{abstract}

Palavras-chave: pré-moldados, concreto armado, patologias.

o contrário do que ocorreu em outros países, os métodos de execução da construção civil no Brasil não acompanharam o desenvolvimento tecnológico. No Brasil, ao longo dos anos não se teve a preocupação em adotar processos construtivos mais racionais; a mão de obra até então, abundante e barata, compensava os gastos com desperdícios e processos com baixo controle (OLIVEIRA, 1997).

Com o aquecimento do mercado e a forte concorrência, as empresas que atuam na construção civil buscam encontrar maneiras de se manter cada vez mais competitivas, de modo que a redução de custos de produção, tempos de execução, menor desperdício, otimização da mão de obra são quesitos que devem ser ponderados. O uso de metodologias que propiciem a industrialização da construção civil se torna uma alternativa interessante, como é o caso da aplicação de elementos pré-moldados.

A Associação Brasileira de Normas Técnicas (ABNT, 1985), em sua NBR 9062/1985 define os

\section{Rogério Alberto Philippsen}

Engenheiro civil pela Universidade Tecnológica Federal do Paraná, UTFPR, Rua Jaciretã, 151, Pato Branco, PR, rogerio.epc@gmail.com

\section{Luiz Antonio Miotti}

Engenheiro civil, professor do curso de Engenharia Civil da Universidade Tecnológica Federal do Paraná, UTFPR, Via do crescimento, Km 1, Pato Branco, PR, lamiotti@gmail.com elementos pré-moldados como peças executadas industrialmente, mesmo em instalações temporárias em canteiros de obras, sob condições rigorosas de controle de qualidade.

Tais elementos representam uma opção válida para racionalizar o processo de produção. Essas peças apresentam algumas características significativas, são elas: rapidez de execução, controle de qualidade, projetos de modulação e relativo nível organizacional de produção (PEDERIVA, 2009).

A racionalização conseguida com o uso de prémoldados permite que os materiais disponíveis para a execução do empreendimento sejam mais bem aproveitados, sem, contudo, demandar profundas alterações tecnológicas (PEDERIVA, 2009).

Na região Oeste de Santa Catarina e Sudoeste do Paraná, as peças pré-fabricadas vêm sendo empregadas frequentemente nas obras. Assim, há a necessidade de conhecer o processo de produção 
de tais peças identificando as falhas que podem ocorrer durante a fabricação, de modo que se possa ter uma indústria que utilize racionalmente seus recursos e ofereça um produto de qualidade para o mercado consumidor.

Realizando visitas a empresas localizadas no Sudoeste do Paraná e Oeste de Santa Catarina foi estudado o processo produtivo de pré-moldados de vigas, pilares, estacas, lajes e galerias pré-fabricadas identificando as patologias mais frequentes e os fatores que podem influenciar na ocorrência dessas patologias durante o processo de produção.

Os objetivos do estudo visaram a identificação da influência do processo produtivo na geração de manifestações patológicas nas peças pré-fabricadas e apresentação de sugestões de melhorias no processo, mediante caracterização do processo de produção das peças pré-fabricadas de concreto armado, identificação de manifestações patológicas oriundas do processo produtivo.

\section{Justificativa}

Com o crescente desenvolvimento da construção civil, a busca por processos construtivos mais eficientes passou a ser uma questão primordial. A forte concorrência faz com que as empresas que atuam no setor busquem novas formas e métodos construtivos, com processo modulado, de maior industrialização, como é o caso dos pré-moldados em concreto armado.

No Brasil, os pré-moldados de concreto armado vêm sendo amplamente difundidos, englobando postes, vigas, pilares, estacas, lajes, entre outros. Não são raras as edificações comerciais e residenciais que são construídas através deste método. Mais especificamente na região Sudoeste do Paraná e Oeste de Santa Catarina, apesar de produzirem peças pré-moldadas, na grande maioria das empresas, o processo de produção é realizado de modo artesanal, sem procedimentos claramente definidos. Assim, comumente veem-se peças de concreto pré-moldado com baixa qualidade sendo empregadas, o que justifica a relevância deste trabalho.

Para que um padrão de qualidade satisfatório seja atingido, capaz de atender a demanda existente, é importante um controle rigoroso durante o processo produtivo das peças e a verificação de manifestações patológicas oriundas deste processo, a fim de minimizá-las ou saná-las, de modo a atestar a funcionalidade, estética e estabilidade dos elementos.

\section{Materiais e programa experimental}

Em relação aos objetivos propostos, o trabalho de pesquisa descritiva está fundamentado em visitas técnicas realizadas às empresas produtoras de pilares, vigas, lajes e galerias pré-fabricadas em concreto armado. No desenvolvimento do trabalho, foram visitadas cinco empresas, localizadas no Oeste de Santa Catarina e Sudoeste do Paraná.

O método utilizado para identificação das patologias mais recorrentes foi o visual, através de técnicas padronizadas de coletas de dados.

Os dados coletados através de trabalho de campo foram obtidos fundamentalmente por observação pessoal, e fundamentado com ilustrações fotográficas.

A coleta de dados foi desenvolvida através de visitas às empresas acima citadas, durante dois meses (setembro e outubro de 2011); para tanto, o delineamento geral da pesquisa demandou cinco etapas consecutivas.

\section{$1^{\text {a }}$ Etapa}

As possíveis empresas a serem visitadas foram identificadas através do conhecimento de obras realizadas por elas na região, das quais se tinha conhecimento, além de pesquisas junto às construtoras locais. A partir disto, foram realizados contatos para agendamento de visita.

\section{$2^{\text {a Etapa }}$}

Elaboração de check-list direcionado ao responsável pelo processo de produção da empresa visando identificar questões como: local de depósito de agregados, cimento, tipos de formas empregadas, produção de concreto, cura, desforma das peças, equipamentos utilizados, dentre outros; aquisição de equipamentos, tais como, máquina fotográfica, trena, bloco de notas, outros. 


\section{$3^{\text {a Etapa }}$}

Visita às empresas que se dispuseram a participar da pesquisa, realizando os seguintes trabalhos:

- $\quad$ entrevista com responsável pela produção da empresa;

- $\quad$ verificação do processo produtivo;

- identificação das patologias; registro fotográfico.

\section{$4^{\text {a }}$ Etapa}

Arquivamento e análise dos registros fotográficos. Seleção das fotos com as principais patologias encontradas.

\section{$5^{\text {a Etapa }}$}

Registro das diversas informações encontradas sobre as empresas: características gerais do processo produtivo; manifestações patológicas nas peças pré-moldadas de concreto armado; sugestão de melhorias no processo produtivo objetivando uma minimização das patologias encontradas.

\section{Resultados e discussões}

Durante o desenvolvimento do trabalho foram visitadas cinco empresas atuantes na produção de peças pré-moldadas de concreto, sendo três localizadas no Sudoeste do Paraná e as demais no Oeste de Santa Catarina, aqui denominadas de E1, E2, E3, E4 e E5, respectivamente. Na Tabela 1 tem-se uma caracterização das empresas visitadas.
Dentre as empresas visitadas, E1, E4 e E5 possuem profissional graduado com ênfase em construção civil como responsável direto pelo setor de produção das peças. Nas demais, o responsável pela produção não apresenta graduação em escola técnica, ocupando a função com base na experiência adquirida ao longo dos anos.

\section{Manifestações patológicas}

Na realização das visitas, foi possível observar a ocorrência de patologias nas peças concretadas. As patologias apresentaram-se sob formas variadas nas cinco empresas, dentre elas destacam-se: manchas, fissuras, quebras, bolhas superficiais, adensamento inadequado (nichos de concretagem), acabamento inadequado.

Fez-se uma amostragem aleatória em 20 peças de cada empresa com o intuito de se verificar a incidência de cada patologia. Com base nesse levantamento, elaboraram-se indicadores das patologias por empresas.

\section{Manchas}

As manchas ocorreram de modo mais significativo nas empresas E1, E3 e E5, conforme Figura 1.

A ocorrência das manchas (Figura 2) pode estar associada à limpeza das formas, ao método de aplicação do desmoldante e também à mistura do concreto. Aplicação dos desmoldantes nestas empresas é realizada com broxas; neste procedimento é comum ocorrerem concentrações de desmoldantes em determinadas regiões da forma em virtude de uma distribuição não homogênea desses materiais.

Tabela 1 - Caracterização das empresas

\begin{tabular}{l|l|l|l|l}
\hline Empresa & Localização & $\begin{array}{l}\text { Produção } \\
\text { ( } \mathbf{m}^{3} / \text { mês) }\end{array}$ & $\begin{array}{l}\text { Funcionários } \\
\text { na Produção }\end{array}$ & $\begin{array}{l}\text { Peças } \\
\text { Produzidas }\end{array}$ \\
\hline E1 & Sudoeste/PR & 300 & 21 a 30 & Lajes, Vigas, Pilares, Placas. \\
\hline E2 & Sudoeste/PR & 150 & 21 a 30 & Galerias, Meio-Fio, Poste, Paver, Placas, Postes. \\
\hline E3 & Sudoeste/PR & 150 & 11 a 20 & Lajes, Vigas, Pilares. \\
\hline E4 & Oeste/SC & 2000 & Mais de 50 & Lajes Alveolares, Vigas, Pilares, Galerias, Placas. \\
\hline E5 & Oeste/SC & 300 & 21 a 30 & Lajes, Vigas, Pilares. \\
\hline
\end{tabular}


Figura 1: Ocorrência de manchas. Fonte: Cleovir José Milani.

Figura 2: Manchas. Fonte: Cleovir José Milani.
Outro quesito importante é a limpeza das formas; antes de cada concretagem é importante realizar uma perfeita limpeza para remoção de óleos, graxas e resquícios de concreto remanescentes das concretagens anteriores.

Em relação à mistura do concreto, nessas empresas foi observado que o concreto não se apresentava perfeitamente homogêneo durante a concretagem, com concentrações de areia em determinados pontos; tal prática pode ter contribuído para a formação das manchas.

\section{Medidas Mitigadoras:}

- Utilizar desmoldantes de baixa viscosidade e aplicá-los com pulverizadores manuais.

- Realizar limpeza das formas antes de cada concretagem.

- Misturar por tempo adequado o concreto e não exceder a capacidade do misturador.

- Evitar excesso de água.
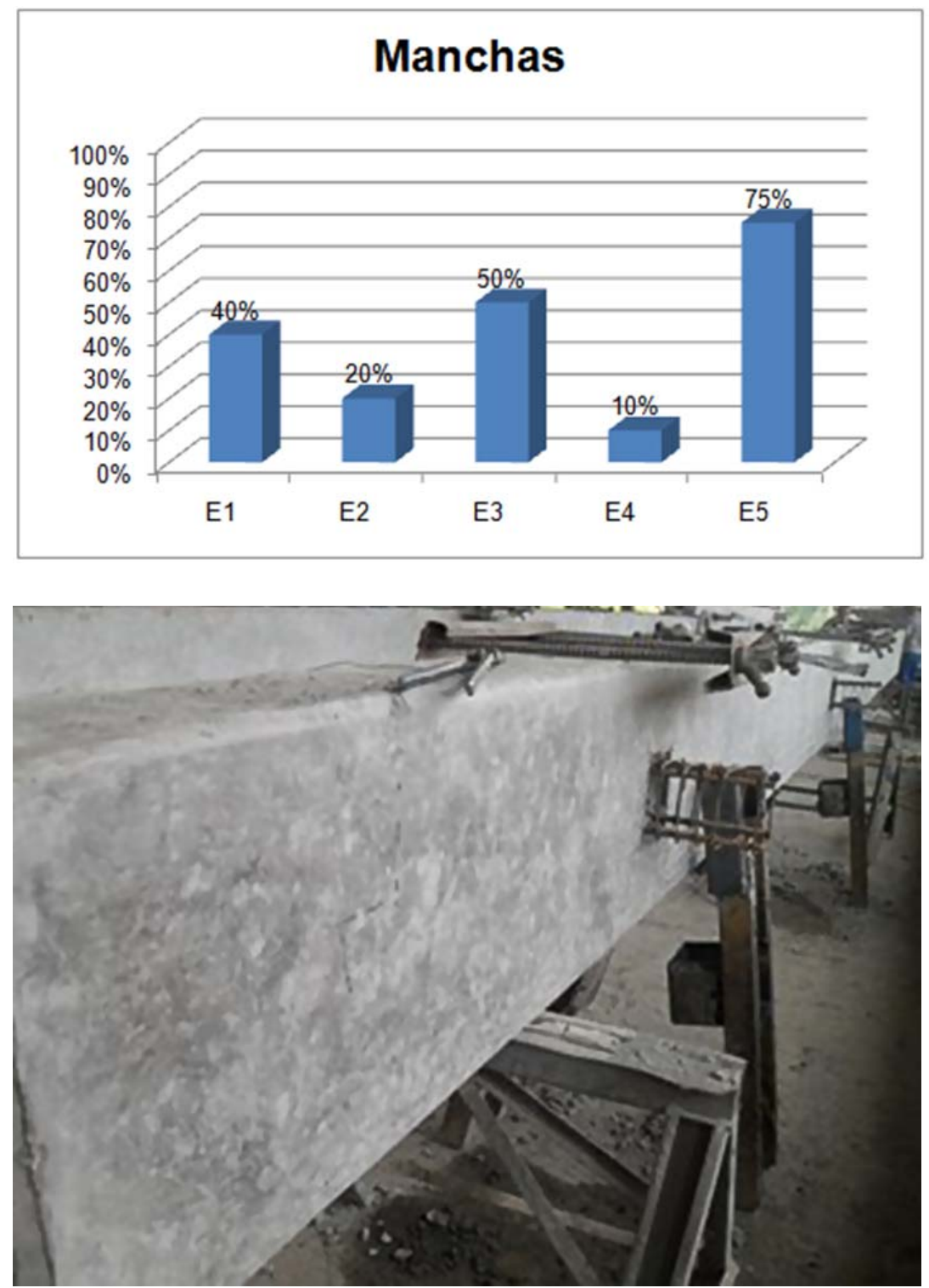

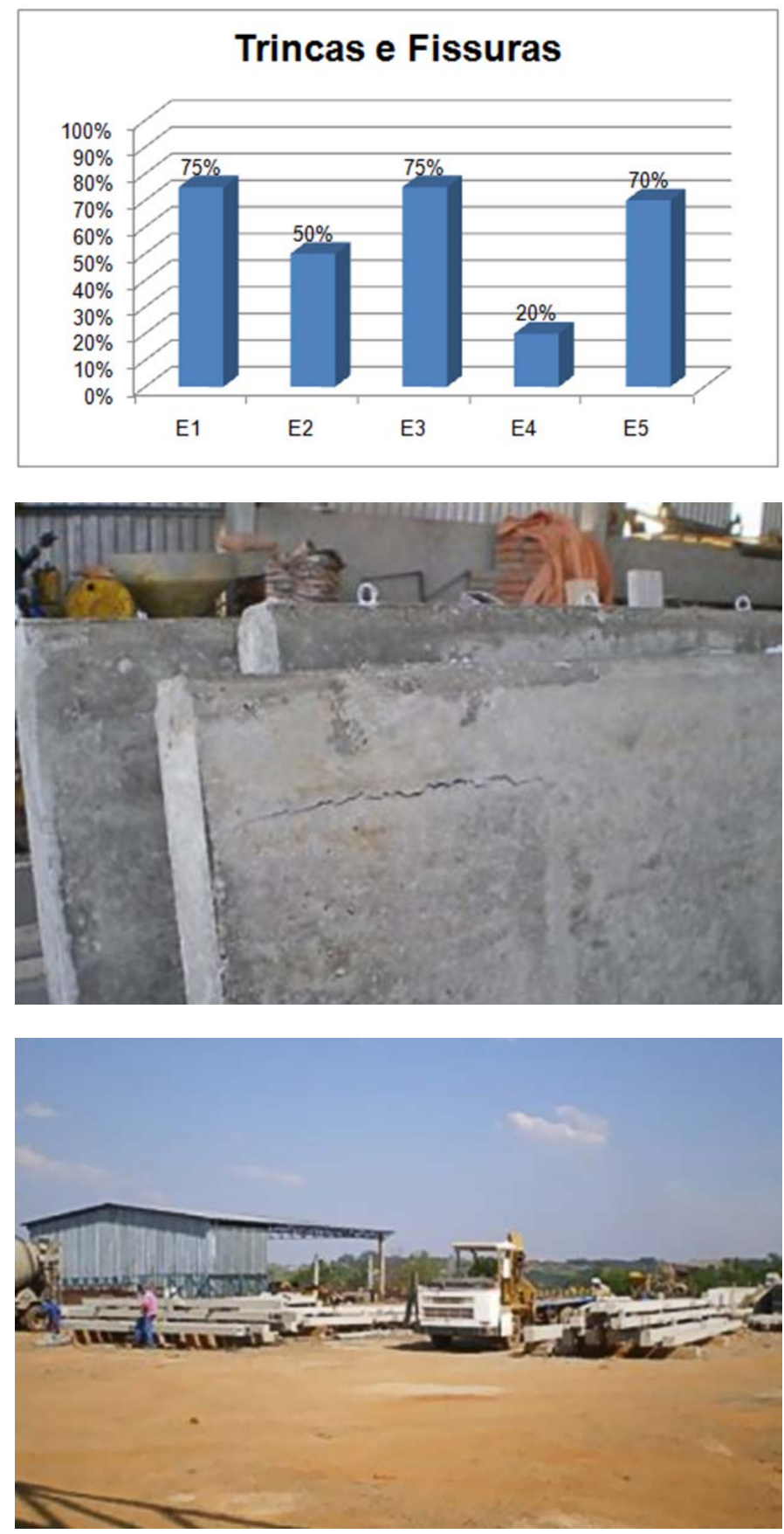

Figura 3: Ocorrência de trincas e fissuras. Fonte: Cleovir José Milani.

Figura 4: Fissuras. Fonte: Cleovir José Milani.

Figura 5: Depósito de peças recém concretadas: incidência direta do sol. Fonte: Cleovir José Milani.

\section{Trincas e fissuras}

Conforme a Figura 3 constatou-se que, nas empresas E1, E2, E3 e E5, a incidência de trincas e fissuras é mais intensa.

A origem das trincas e fissuras (Figura 4) pode estar relacionada ao tipo de cimento utilizado pelas empresas, no caso o CP V ARI, e também ao procedimento de cura das peças concretadas.
Conforme observado nas visitas, as empresas não realizam a cura adequada das peças; os elementos concretados permanecem geralmente por um dia nas formas, quando então são desmoldados e levados ao estoque, ficando diretamente expostos ao sol, o que pode contribuir para o surgimento de trincas por retração. As peças em estoque não são umedecidas diariamente para minimizar tais efeitos (Figura 5). 

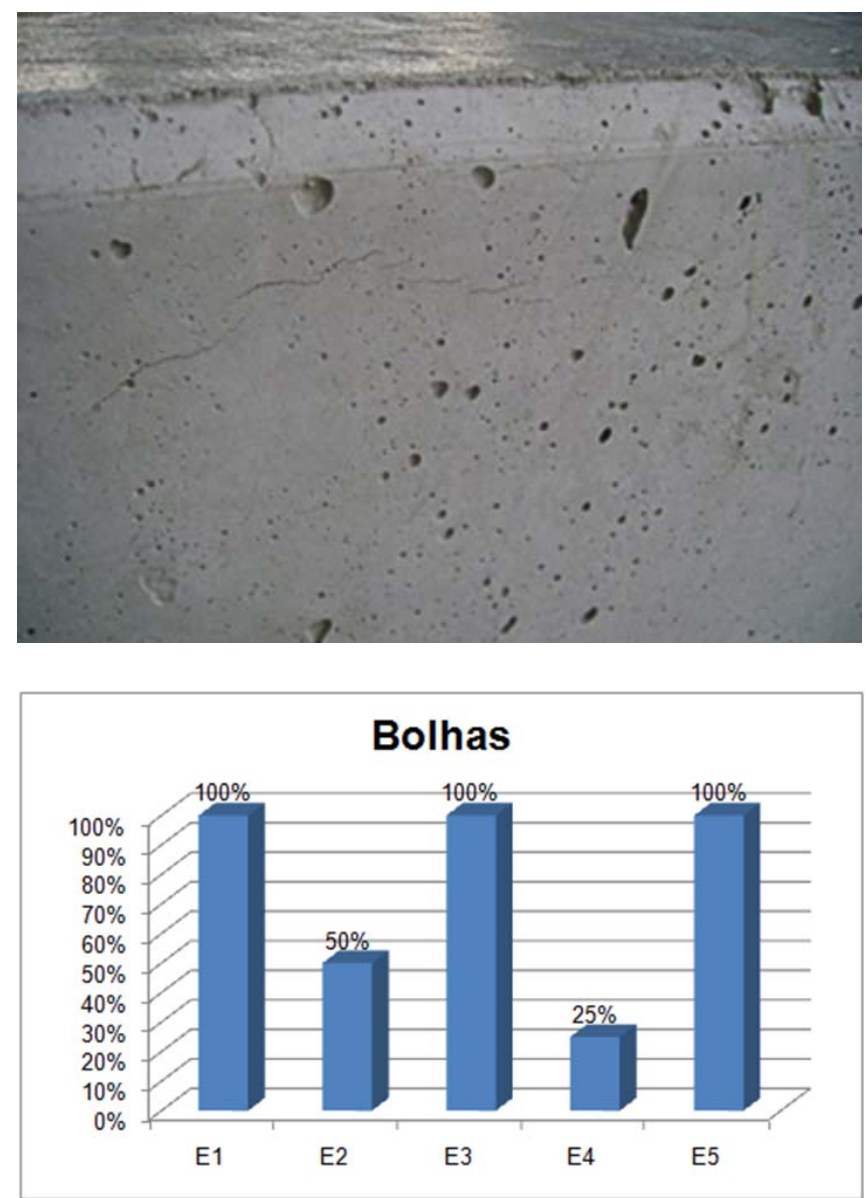

Figura 6: Bolhas superficiais. Fonte: Cleovir José Milani.

Figura 7: Ocorrência de bolhas. Fonte: Cleovir José Milani.
Com relação às trincas e fissuras, a empresa E4 apresentou índice menos significativo que as demais. Isso pode ser correlacionado ao fato de seu processo de cura ser diferenciado. Após a concretagem, na empresa E4 é colocada sobre as peças uma manta plástica de cura a fim de evitar a perda excessiva de água para o ambiente. Tal prática, apesar de não extinguir completamente a patologia, minimizou sua ocorrência.

Medidas Mitigadoras:

- Realizar cura úmida constante, da concretagem até a expedição das peças para a obra.

- Com o concreto ainda estado fresco, aplicar manta de cura sobre as peças concretadas.

\section{Bolhas superficiais}

Dentre as patologias constatadas, as bolhas superficiais (Figura 6) foram a patologia de maior incidência dentre todas as identificadas.
Com relação à ocorrência de bolhas, pela Figura 7 foi possível constatar que essas bolhas se manifestaram de modo mais intenso nas peças produzidas pelas empresas E1, E3 e E5.

O surgimento dessa patologia pode estar correlacionado ao tipo de desmoldante empregado nas formas e também à vibração inadequada. Essas três empresas utilizam desmoldantes a base de óleos minerais; todavia, segundo a literatura, esse tipo de desmoldante pode propiciar o surgimento de bolhas de superfície. Com relação à vibração, todas as três empresas utilizam o vibrador tipo agulha (de mangote).

Durante as visitas, foi possível observar que a vibração não era executada de modo correto; o vibrador agulha utilizado para adensar peças grandes era o mesmo utilizado nas peças menores, desse modo nos elementos de menores dimensões além de a vibração ocorrer de modo excessivo, ela era executada próxima das faces das formas o que 
Figura 8: Vibração inadequada: próximo às faces da forma. Fonte: Cleovir José Milani.

Figura 9: Adensamento inadequado. Fonte: Cleovir José Milani.

Figura 10: Acabamento Inadequado. Fonte: Cleovir José Milani. pode ter contribuído para a ocorrência das bolhas, conforme Figura 8.

Medidas Mitigadoras:

- Não utilizar desmoldantes a base de óleos minerais.

- Concretar as peças com concreto autoadensável (CAA).

- Não vibrar excessivamente o concreto nas proximidades das faces.
- Utilizar vibradores compatíveis com as dimensões das peças a serem concretadas.

\section{Falhas de acabamento e adensamento}

Dentre as patologias constatadas, observou-se que as peças com maior índice de problemas de acabamento (Figura 9) e falhas de concretagem (Figura 10) ocorreram na empresa E2.
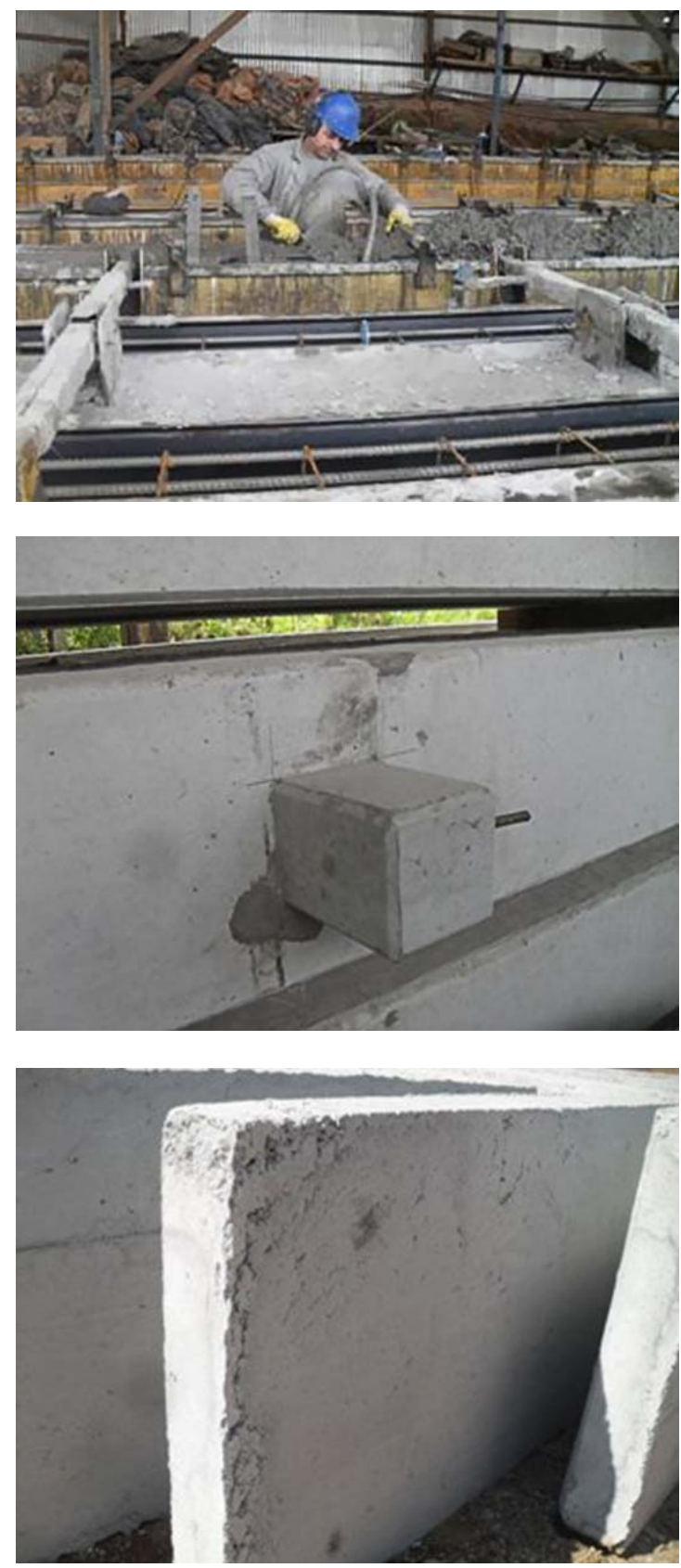

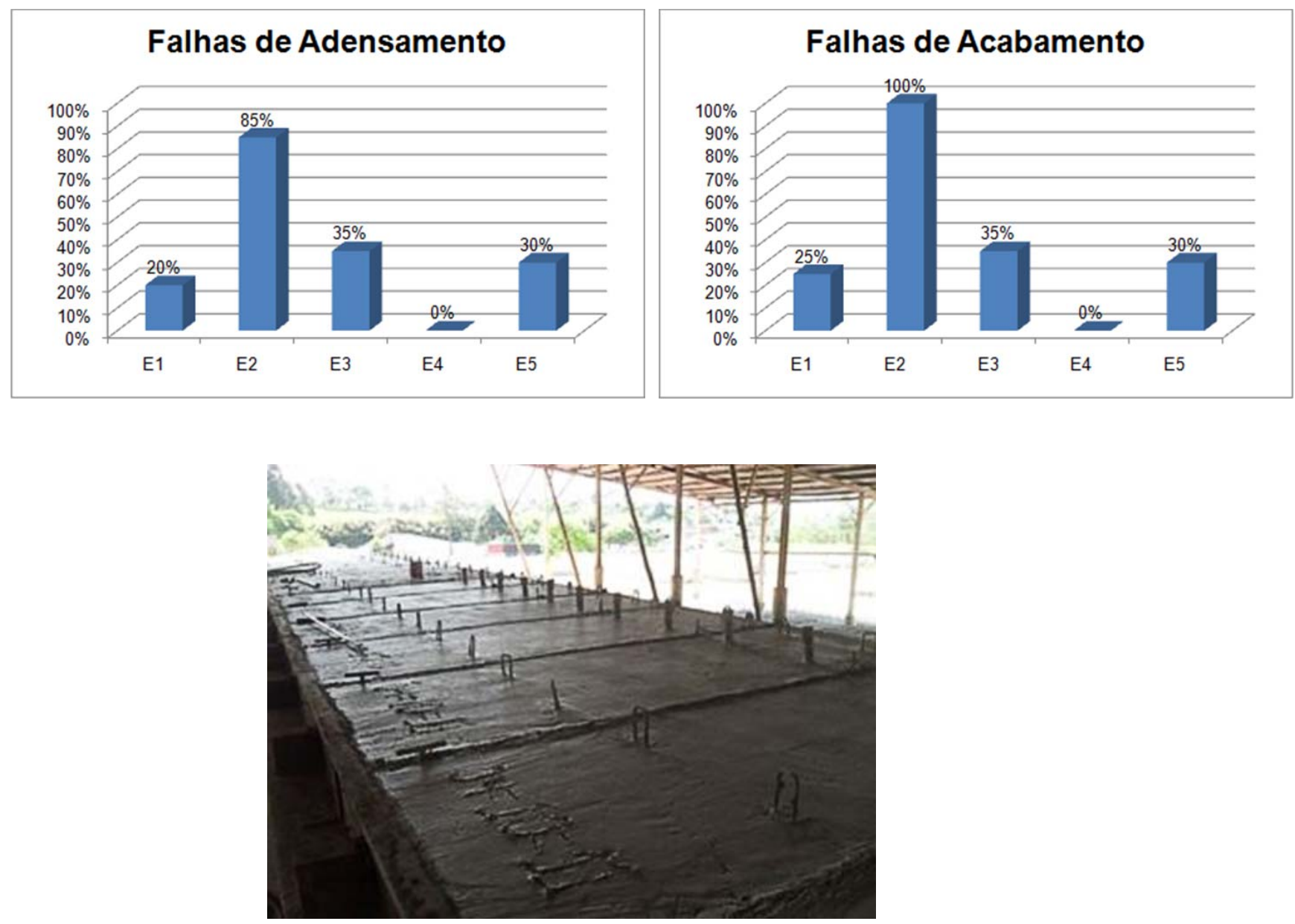

Figura 11: Ocorrência de falhas de adensamento e falhas de acabamento. Fonte: Cleovir José Milani.

Figura 12: Concretagem das galerias. Fonte: Cleovir José Milani.
Pela Figura 11 percebeu-se que as falhas de adensamento atingiram $85 \%$ das peças observadas enquanto que as falhas de acabamento foram identificadas em todas as peças. Tais peças referemse às galerias em formato $\mathrm{L}$.

As peças que apresentaram tais patologias possuem grandes dimensões (2,5 metros de altura e 2,0 metros de largura) e, pelo sistema de formas adotado, a concretagem é realizada em uma única etapa. Desse modo, o concreto é lançado de alturas elevadas, o que contribui para a segregação de seus elementos constituintes. Além disso, a vibração do concreto é realizada por vibradores tipo agulha; por serem concretadas em uma única etapa (as formas não possuem janelas de concretagem), o vibrador não tem capacidade de vibrar as camadas inferiores; nestas regiões, em $100 \%$ das peças observadas, constataram-se falhas no adensamento do concreto e falhas de acabamento.
Notou-se também que as galerias $L$ após concretadas não são "reguadas" para que a sua face superior torne-se plana e com acabamento uniforme. Terminada a concretagem, os funcionários são orientados a apenas alisar a superfície com a colher de pedreiro, o que não deixa a face superior perfeitamente nivelada e lisa (Figura 12).

Medidas Mitigadoras:

Utilizar o concreto autoadensável.

- $\quad$ Alterar sistema de formas para que o concreto não necessite ser lançado de grandes alturas.

- $\quad$ Abrir janelas intermediárias de concretagem.

- Reguar a face superior da galeria.

- Utilizar vibrador adequado às dimensões da peça. 
Figura 13: Quebra. Fonte: Cleovir José Milani.

Figura 14: Ocorrência de quebras. Fonte: Cleovir José Milani.

\section{Quebras}

Durante as visitas, viu-se que as quebras (Figura 13) não se apresentaram como patologias de grande incidência nas empresas observadas.

Apenas na empresa $E 1$, as quebras foram mais significativas com cerca de $15 \%$ das peças observadas, conforme Figura 14.

As quebras observadas na empresa foram oriundas da movimentação interna das peças (desforma e estocagem). A empresa E1 não possui pontes rolantes que unem a produção com o setor de estocagem; esse transporte é realizado por meio de caminhões. Assim, ocorrência de choques mecânicos é maior o que gera as quebras e lascas das peças observadas.
Medidas Mitigadoras:

- Realizar o transporte das peças por meio de pontes rolantes.

- Proteger as extremidades das peças durante a movimentação.

\section{Conclusões}

O estudo mostrou as seguintes patologias:

O surgimento das bolhas peças produzidas pode ser função do desmoldante empregado e da vibração executada de modo inadequado.

Os desmoldantes a base de óleos minerais podem propiciar o surgimento de bolhas de
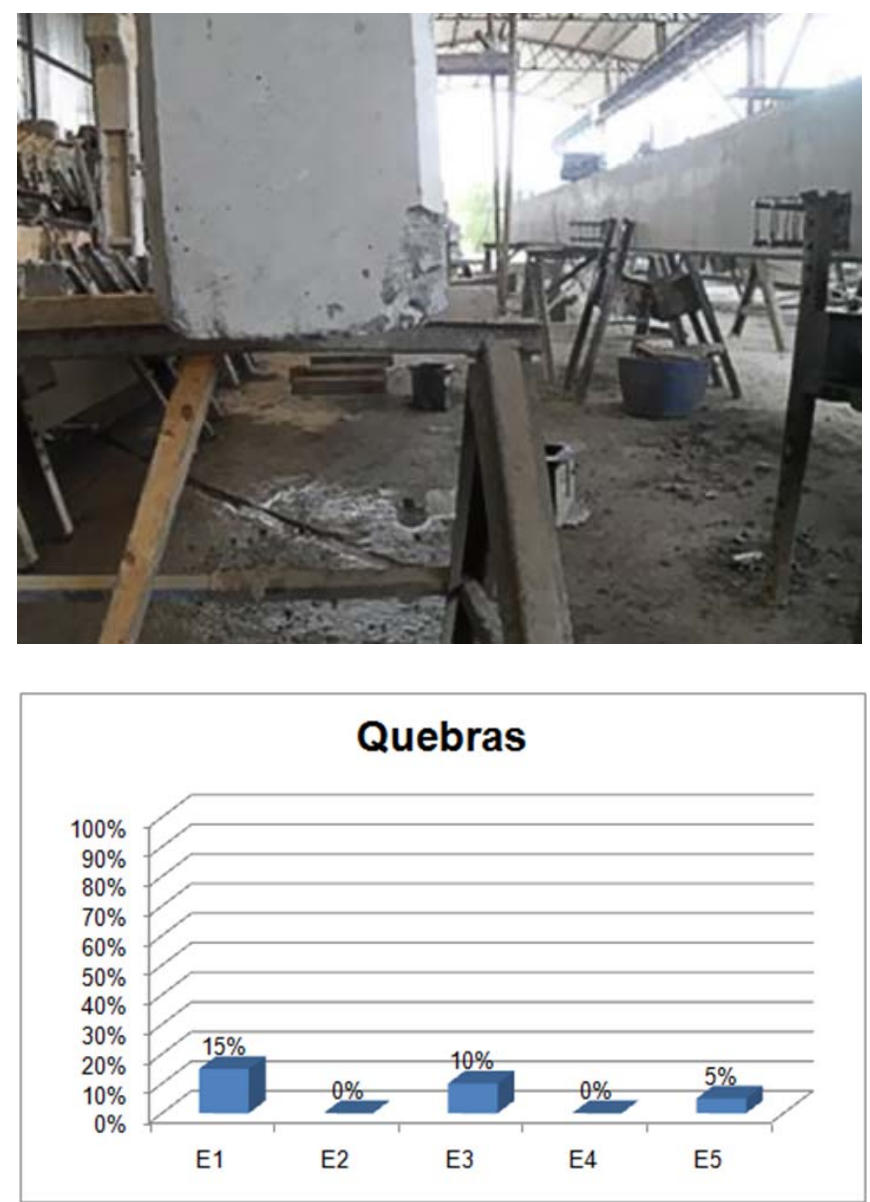
superfície e, além disso, a vibração não era feita corretamente.

Para adensar as peças grandes e as pequenas, o mesmo vibrador é utilizado; deste modo, nos elementos de menores dimensões a vibração ocorria de modo excessivo e executada próxima das faces, o que pode ter ocasionado a ocorrência das bolhas.

As trincas e fissuras tiveram maior incidência nas empresas E1, E2, E3 e E5. Tais ocorrências podem estar atreladas ao tipo de cimento utilizado pelas empresas, no caso o CP V ARI, mas principalmente ao procedimento de cura.

As manchas foram mais incidentes nas empresas E3 e E5. Isso pode ser consequência do procedimento de aplicação do desmoldante e também da mistura do concreto.

Na empresa E2 constatou-se a ocorrência de peças com falhas de acabamento e falhas no adensamento das galerias. Essas peças são de grandes dimensões e, pelo formato das formas, a concretagem ocorre em uma única etapa.

Observou-se que as empresas E1, E2, E3 e E5 apresentaram a maior incidência de patologias. Tal fato pode estar correlacionado ao processo produtivo, executado com controle menos rigoroso das etapas, metodologias, materiais e mão de obra menos especializada.

A empresa E4 apresentou-se melhor estruturada que as demais, e por consequência, a incidência de patologias foi menos intensa.

Na empresa E4, a mão de obra recebe treinamento técnico com maior frequência, enquanto que na maior parcela das demais, os funcionários não recebem treinamento, sendo o conhecimento transmitido de colaborador a colaborador conforme a convivência entre eles.

Na empresa E4 é feito controle eletrônico da umidade da areia, dosagem do concreto em massa; emprega o concreto autoadensável nas peças e realiza algum procedimento de cura.

\section{Referências bibliográficas}

OLIVEIRA, C. S. P. As principais características da mão-deobra da construção civil que interferem na filosofia da qualidade. Anais... XVII Encontro Nacional de Engenharia de Produção - Enegep 1997.

ASSOCIAÇÃO BRASILEIRA DE NORMAS TÉCNICAS. NBR 9062: Projeto e Execução de Estruturas de Concreto Pré-Moldado. Rio de Janeiro, 1985.

PEDERIVA, P. F. Comparação de custos envolvidos na construção de pavilhões com estruturas pré-moldadas e moldadas in loco. Monografia [Graduação em Engenharia Civil] - ljuí, RS: Universidade Regional do Noroeste do Estado do Rio Grande do Sul, 2009. 